\title{
Interactions of Aminopropyl-Azithromycin Derivatives, Precursors in the Synthesis of Bioactive Macrozones, with E. coli Ribosome: NMR and Docking Studies
}

\author{
Ivana Mikulandra ${ }^{1}$, Tomislav Jednačak ${ }^{1} \oplus$, Branimir Bertoša ${ }^{1}$, Jelena Parlov Vuković ${ }^{2}$, Iva Kušec ${ }^{1}$ \\ and Predrag Novak ${ }^{1, *}$ \\ 1 Department of Chemistry, Faculty of Science, University of Zagreb, Horvatovac 102a, \\ HR-10000 Zagreb, Croatia; ivana.mikulandra@chem.pmf.hr (I.M.); tjednacak@chem.pmf.hr (T.J.); \\ branimir.bertosa@chem.pmf.hr (B.B.); kuseciva38@gmail.com (I.K.) \\ 2 INA-Industrija Nafte d.d., Refining \& Marketing, Central Testing Laboratory, Lovinčićeva bb, \\ HR-10002 Zagreb, Croatia; Jelena.Parlov-Vukovic@ina.hr \\ * Correspondence: pnovak@chem.pmf.hr; Tel.: +385-1-460-6184
}

\section{check for} updates

Citation: Mikulandra, I.; Jednačak, T.; Bertoša, B.; Parlov Vuković, J.; Kušec, I.; Novak, P. Interactions of Aminopropyl-Azithromycin Derivatives, Precursors in the Synthesis of Bioactive Macrozones, with E. coli Ribosome: NMR and Docking Studies. Materials 2021, 14 5561. https://doi.org/10.3390/ ma14195561

Academic Editor: Eri Yoshida

Received: 3 September 2021

Accepted: 22 September 2021

Published: 25 September 2021

Publisher's Note: MDPI stays neutral with regard to jurisdictional claims in published maps and institutional affiliations.

Copyright: (c) 2021 by the authors. Licensee MDPI, Basel, Switzerland. This article is an open access article distributed under the terms and conditions of the Creative Commons Attribution (CC BY) license (https:// creativecommons.org/licenses/by/ $4.0 /)$.

\begin{abstract}
The structure and interactions of several aminopropyl-azithromycin derivatives (1a-c) have been studied by using NMR spectroscopy and docking calculations. Compounds $\mathbf{1 a}-\mathbf{c}$ are precursors in the synthesis of macrozones, novel bioactive azithromycin-thiosemicarbazone conjugates active against some resistant bacterial strains. Today, bacterial resistance is considered as one of the major threats to human health. Knowledge on drug binding mode and conformations is one of the key factors in the process of designing molecules to fight resistance. In solution state, compounds 1a and $\mathbf{1 c}$ exist in the 3-endo-folded-out conformation, while $\mathbf{1 b}$ adopts a classical folded-out conformation. ${ }^{13} \mathrm{C}$ and ${ }^{15} \mathrm{~N}$ CPMAS NMR spectra pointed towards similar structures in the solid state. The transferred NOESY NMR spectra confirmed binding to the E. coli ribosome and suggest that dominant conformations in the bound state resemble those in the free one. STD experiments identified reactive groups of $\mathbf{1 a}-\mathbf{c}$ in close contact with the ribosome resembling binding epitopes observed for the related 15-membered macrolides. Docking studies revealed that the studied compounds bind to the same ribosome binding pocket similarly to erythromycin in the crystal state, and that the binding is achieved through H-bonds and van der Waals interactions. The bound conformation is the same as determined by NMR. STD enhancements observed for methylene protons in the aminopropyl side chain indicate additional interactions which contribute to the overall binding energy.
\end{abstract}

Keywords: azithromycin derivatives; interactions; ribosome-bound epitopes; NMR spectroscopy; docking

\section{Introduction}

Macrozones belong to a novel class of azithromycin-thiosemicarbazone conjugates that exhibit very good antibacterial activities against both susceptible and some resistant bacterial strains, such as efflux- and MLS (macrolides-lincosamides-streptogramines)resistant $S$. aureus, S. pneumoniae and S. pyogenes strains [1,2]. Macrolide antibiotics, such as azithromycin, have been in clinical use for over 50 years, mostly due to their high efficacy, safety and favorable pharmacokinetics. They are prescribed to treat upper and lower respiratory tract infections [3]. Macrolides bind to the 23S rRNA of the 50S subunit, near or at the peptidyl transferase center (PTC), block the nascent peptides exit tunnel and thus inhibit the synthesis of bacterial proteins. However, emerging bacterial resistance to antibiotics compromises their use as effective antimicrobials and represents a serious threat to human health worldwide. There are several resistance mechanisms to macrolides and the most frequent are modifications in the ribosome target, efflux pumps, inactivation of the compound and mutations in the $23 S$ rRNA and some proteins [4]. Therefore, the 
discovery of novel and safer macrolides active against resistant pathogenic bacteria is today an ultimate goal of antibiotic drug design.

As above mentioned, macrozones are novel hybrid azithromycin derivatives designed to overcome bacterial resistance [1,2]. Structurally, they consist of a polyfunctional macrolactone ring with two saccharide units (desozamine and cladinose) and a thiosemicarbazone moiety attached to it at certain positions (Scheme 1).

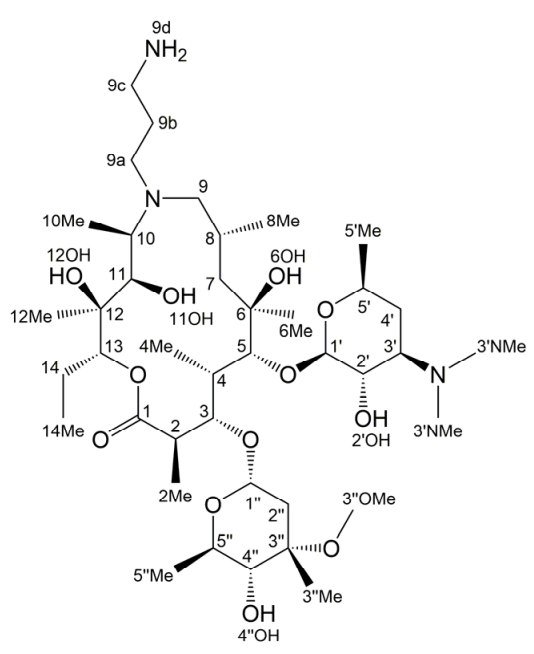

$1 \mathrm{a}$

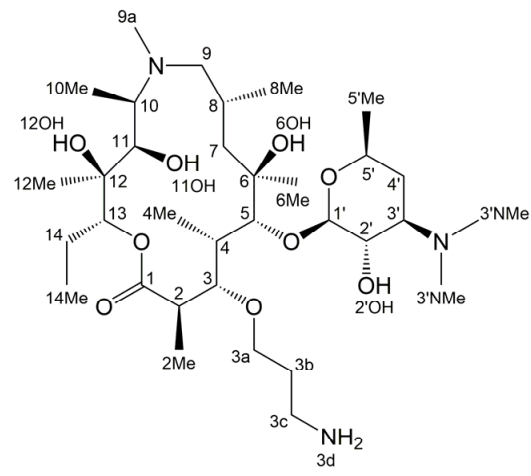

$1 \mathrm{~b}$

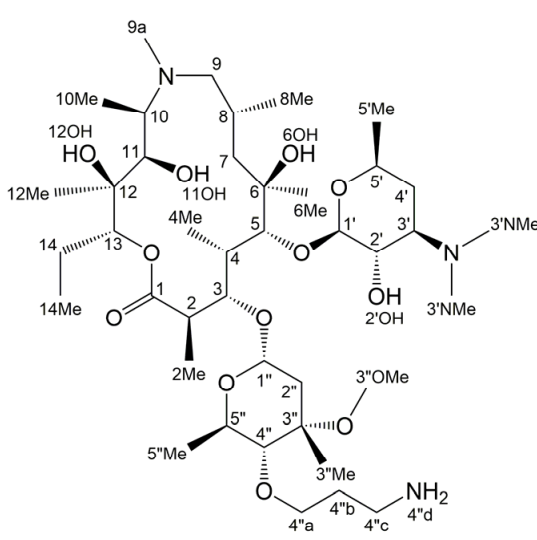

$1 \mathrm{c}$

Scheme 1. Structure and atom numbering of aminopropyl-azithromycin derivatives, precursors in the synthesis of macrozones.

A crucial step in the discovery of novel compounds for preventing resistance is to understand how macrolides interact with their biological target ribosome. Crystal structures of some ribosome-macrolide complexes have been solved [5-7] and they elucidate important binding mechanisms of macrolides to ribosomes. However, we believe that the process of new antibiotic design should also include elucidation of the solution-state structures and dynamics of free and bound ligand molecules, since the structural features of the complex may not be exactly the same in solution and in the solid state [8-14].

Here, we report on interactions of aminopropyl-azithromycin derivatives 1a-c (Scheme 1), precursors in the synthesis of macrozones, with the ribosome isolated from E. coli. Compounds 1a-c also showed promising antibacterial activities against some bacterial strains (Table 1).

Table 1. In vitro antibacterial activity (MIC, $\mu \mathrm{g} / \mathrm{mL}$ ) for aminopropyl-azithromycin derivatives 1a-c.

\begin{tabular}{|c|c|c|c|c|c|c|c|c|}
\hline \multirow[t]{3}{*}{ Compound } & 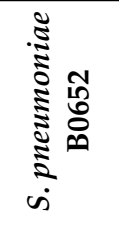 & 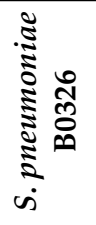 & 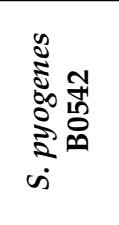 & 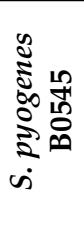 & 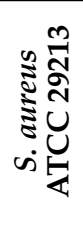 & 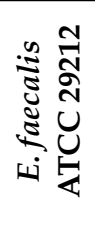 & 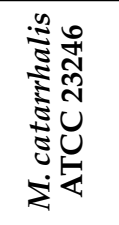 & 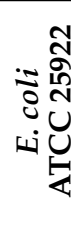 \\
\hline & eryS & $\mathbf{M}$ & eryS & $\mathbf{M}$ & eryS & & & \\
\hline & \multicolumn{8}{|c|}{$\operatorname{MIC}(\mu \mathrm{g} / \mathrm{mL})^{a}$} \\
\hline $1 \mathrm{a}$ & 1 & 64 & 0.5 & 64 & 8 & 64 & 4 & 32 \\
\hline $1 b$ & 16 & 64 & 32 & 64 & $>64$ & $>64$ & 2 & 64 \\
\hline $1 c$ & 0.5 & 16 & 2 & 32 & 16 & 64 & 2 & 32 \\
\hline azithromycin & $\leq 0.125$ & 16 & $\leq 0.125$ & 8 & 1 & 8 & $\leq 0.125$ & $>64$ \\
\hline
\end{tabular}

${ }^{a}$ minimum inhibitory concentration. 
We applied NMR techniques such as nuclear Overhauser effect spectroscopy (NOESY) and saturation transfer difference (STD) spectroscopy to study the binding of $\mathbf{1 a - c}$ and to determine their ribosome-bound epitopes. Molecular docking was used to characterize complexes of $1 \mathbf{a}-\mathbf{c}$ with the ribosome and to elucidate the most important sites of interactions.

\section{Materials and Methods}

\subsection{Antibacterial Testing}

Minimum inhibitory concentrations (MICs) were determined according to guidelines of the Clinical Laboratory Standards Institute (CLSI). Compounds were prepared as $10 \mathrm{mg} \mathrm{mL}^{-1}$ solutions in dimethyl sulfoxide (DMSO). Final dilutions of the tested compounds were prepared in the $64-0.125 \mu \mathrm{g} \mathrm{mL}^{-1}$ concentration range. The validity of the screen was confirmed by determining MIC values for the reference antibiotic, azithromycin.

\subsection{NMR}

The structure of the prepared precursors was characterized by NMR spectroscopy. One- and two-dimensional NMR spectra were recorded on Bruker Avance III HD 400 and Bruker Avance NEO 600 spectrometers (Bruker Biospin GmbH, Rheinstetten, Germany) equipped with $5 \mathrm{~mm}$ inverse (TCI) cryogenically cooled probes and z-gradient accessories. Samples were measured at room temperature in $\mathrm{CD}_{3} \mathrm{CN}, \mathrm{CDCl}_{3}$ and Tris- $\mathrm{d}_{11}$ buffer with TMS as the internal standard. The sample concentration was $20 \mathrm{mg} \mathrm{mL}^{-1}$ in $\mathrm{CD}_{3} \mathrm{CN}$ and $\mathrm{CDCl}_{3}$ and $2-4 \mathrm{mg} \mathrm{mL}^{-1}$ in Tris- $\mathrm{d}_{11}$ buffer.

Proton NMR spectra were recorded with $16-128$ scans, $11.9 \mathrm{kHz}$ spectral width and a digital resolution of $0.36 \mathrm{~Hz}$ per point. For DEPTQ spectra, 3072 scans were used with a spectral width of $35 \mathrm{kHz}$ and digital resolution of $0.67 \mathrm{~Hz}$. In COSY experiments, spectral conditions were: $4-5$ scans, $5.6 \mathrm{kHz}$ spectral width, digital resolution of $5.46 \mathrm{~Hz}$ per point in $\mathrm{f} 2$ and $43.7 \mathrm{~Hz}$ per point in $\mathrm{f} 1$ dimension. Spectral conditions for edited-HSQC and HMBC spectra were as follows: $9.6 \mathrm{kHz}$ spectral width in $\mathrm{f} 2$ and $27.1 \mathrm{kHz}$ in $\mathrm{f} 1$ dimension, digital resolution of 4.69 and $212.3 \mathrm{~Hz}$ per point in $\mathrm{f} 2$ and $\mathrm{f} 1$ dimensions, respectively. For both HSQC and HMBC spectra, $4 \mathrm{~K}$ data points were applied in the time domain and the number of increments for each data set was 256 . The number of scans varied between 40 and 64 for HSQC and between 70 and 160 scans for HMBC spectra.

The NOESY spectra were recorded with 50 scans per increment and a relaxation delay of $2 \mathrm{~s}$. Spectral width was $9.6 \mathrm{kHz}$ in both dimensions, and $2 \mathrm{~K}$ data points were used in the time domain with $1 \mathrm{~K}$ increments in each data set. The digital resolution was $9.39 \mathrm{~Hz}$ per point in the $\mathrm{f} 2$ dimension and $18.7 \mathrm{~Hz}$ per point in the $\mathrm{f} 1$ dimension. NOESY spectra were obtained with a mixing time of $400 \mathrm{~ms}$.

In trNOESY experiments recorded in Tris- $\mathrm{d}_{11}$ buffer, the same conditions were used except for mixing time $(75 \mathrm{~ms})$, number of scans $(80)$, time domain $(2 \mathrm{~K} \times 512)$ and digital resolution in $\mathrm{f} 1$ dimension ( $37.5 \mathrm{~Hz}$ per point).

The measuring conditions for ROESY spectra were: 80 scans, $3.2 \mathrm{kHz}$ spectral width in both dimensions, digital resolution of 3.1 and $25.5 \mathrm{~Hz}$ per point in the $\mathrm{f} 2$ and $\mathrm{f} 1$ dimensions, respectively. Data were collected into a $2 \mathrm{~K} \times 256$ acquisition matrix.

For trNOESY and STD experiments, completely deuterated ribosomes isolated from $E$. coli MRE 600 strain, purchased from Dr. Kalju Vanatalu, Leete Str. 13, 11313 Tallinn, Estonia, were used. The ribosomes were added into the solutions of $\mathbf{1 a}-\mathbf{c}$ until the final concentration of $1.25 \mu \mathrm{mol} \mathrm{L}-1$ was achieved. STD and trNOESY measurements were carried out with a total volume of $500 \mu \mathrm{L}$ and a macrolide to ribosome ratio of approximately 3500:1. Onedimensional STD NMR spectra were acquired with 256 scans, $9 \mathrm{kHz}$ spectral width and $3 \mathrm{~s}$ saturation time. A total of $32 \mathrm{~K}$ data points were collected in the time domain. For different precursors, saturation frequency varied, and it was switched from on-resonance (8-11 ppm) to off-resonance (50 ppm) after each scan. Selective saturation of the ribosome was performed using a $50 \mathrm{~ms}$ Gauss pulse. 
Solid-state NMR spectra were recorded using Bruker Avance Neo 300 and 400 spectrometers equipped with broad-band magic angle spinning (MAS) probes. The samples were spun in $4 \mathrm{~mm}$ rotors at the magic angle with $10 \mathrm{kHz}$. Cross-polarization (CP) MAS NMR experiments were conducted using standard CPMAS pulse sequences with highpower decoupling during acquisition. ${ }^{13} \mathrm{C}$ and ${ }^{15} \mathrm{~N}$ CPMAS NMR spectra were acquired with 16-1024 and 16384 scans, and the recycle delay was 7.0 and $3.5 \mathrm{~s}$, respectively. The spectra were externally referenced to glycine.

\subsection{Molecular Docking}

Using ChemDraw, 3D structures of compounds 1a-c were generated. The ribosome structure was prepared for docking study using the Maestro program, starting from the crystal structure of the Escherichia coli ribosome (PDB code: 4V7U). Systems were prepared for docking calculations with Autodock Tools [15] using the default settings and maximum grid size $(126 \AA \times 126 \AA \times 126 \AA)$. The center of the grid was determined according to the position of the erythromycin molecule in the $\mathrm{X}$-ray structure. Docking calculations were accomplished using Autodock Vina 1.1.2 [16]; exhaustiveness was set to 32. The results were analyzed using Maestro and VMD [17].

\section{Results and Discussion}

The aminopropyl-azithromycin derivatives $\mathbf{1 a}-\mathbf{c}$ are precursors in the synthesis of macrozones, the novel bioactive azithromycin-thiosemicarbazone conjugates [1,2]. The compounds 1a-c have shown promising activity against some Gram-positive and Gramnegative bacteria, including efflux-resistant S. pneumoniae and S. pyogenes strains and a Gram-negative $E$. coli strain against which azithromycin is inactive (Table 1).

We employ here a combination of experimental (NMR) and computational methods (molecular docking) to study the structure and interactions of 1a-c with the ribosome isolated from E. coli. Prior to binding studies, we identified and elucidated the structures of precursors in solution and solid state.

\subsection{Structure Elucidation of 1a-c}

To determine the 2D structure of macrozone precursors in solution, we employed one$\left({ }^{1} \mathrm{H}\right.$ and DEPTQ) and two-dimensional NMR techniques (COSY, edited-HSQC and HMBC). Spectral analysis confirmed the structure as depicted in Scheme 1. It has already been demonstrated that 15-membered macrolides adopt two main conformations in solution, e.g., folded-in and folded-out, referring to the inward or outward folding of the ring fragment C2-C5 (Scheme 1). The percentage of the two conformers also depends on the experimental conditions, such as temperature and solvent polarity [8-10].

An intermediate conformation named 3-endo-folded-out has also been reported for 15-membered macrolides [10]. Vicinal coupling constants ${ }^{3} \mathrm{~J}_{\mathrm{H} 2, \mathrm{H} 3}$ and NOE proton-proton contacts $\mathrm{H} 3-\mathrm{H} 11$ and $\mathrm{H} 4-\mathrm{H} 11$ can serve as good indicators of the aglycone ring folding. Hence, the folded-out conformers have larger ${ }^{3} \mathrm{~J}_{\mathrm{H} 2, \mathrm{H} 3}$ values $(\approx 10 \mathrm{~Hz})$, larger torsion angles between atoms $\mathrm{H} 2$ and $\mathrm{H} 3\left(\approx \pm 180^{\circ}\right)$ and exhibit a close space approach of protons $\mathrm{H} 4$ and $\mathrm{H} 11$. Lower ${ }^{3} \mathrm{~J}_{\mathrm{H} 2, \mathrm{H} 3}$ values $(\approx 2-3 \mathrm{~Hz})$, lower torsion angles $\left(\approx 100^{\circ}\right)$ and a close contact of atoms $\mathrm{H} 3$ and $\mathrm{H} 11$ are characteristic of the folded-in conformers [8,11,14].

Several other NOE cross peaks such as $\mathrm{H} 2-\mathrm{H} 4$ and H5-H6Me are indicative of the folded-out structures, and $\mathrm{H} 4-\mathrm{H} 6 \mathrm{Me}$ and $\mathrm{H} 3-\mathrm{H} 8$ are indicative of the folded-in structures. In order to establish whether conformational changes occur upon binding of $\mathbf{1 a}-\mathbf{c}$ to the ribosome, we first recorded NOESY spectra in a solution of free molecules and measured $\mathrm{H} 2-\mathrm{H} 3$ coupling constants to assess the unbound conformations. We obtained ${ }^{3} J_{\mathrm{H} 2, \mathrm{H} 3}$ values from the proton spectra in buffered $\mathrm{D}_{2} \mathrm{O}$ and acetonitrile- $\mathrm{d}_{3}$ solutions (Table 2) and recorded NOESY spectra to determine distinctive proton-proton NOE connectivities for 1a-c (Table 3). The compound $\mathbf{1} \mathbf{b}$ had a large ${ }^{3} \mathrm{~J}_{\mathrm{H} 2, \mathrm{H} 3}$ coupling constant in both solvents $(\approx 10 \mathrm{~Hz})$, suggesting the torsional angle of approximately $180^{\circ}$, and displayed NOE cross peaks characteristic of the folded-out conformation (H4-H11, H2-H4, H5-H6Me). The 
other two compounds showed smaller ${ }^{3} J_{\mathrm{H} 2, \mathrm{H} 3}$ values $(\approx 5-6 \mathrm{~Hz})$ intermediate between the two conformational families, suggesting smaller torsional angles, and exhibit $\mathrm{H} 4-\mathrm{H} 11$, but no H3-H11 contacts in buffered $\mathrm{D}_{2} \mathrm{O}$ and acetonitrile- $\mathrm{d}_{3}$. This observation is consistent with 3-endo-folded-out structures, such as those observed for 15-membered 6-O-methyl homoerythromycins [10].

Table 2. Vicinal coupling constants ${ }^{3} J_{\mathrm{H} 2, \mathrm{H} 3}$ for $\mathbf{1 a}-\mathbf{c}$ in free state.

\begin{tabular}{ccc}
\hline \multirow{2}{*}{ Compound } & \multicolumn{3}{c}{${ }^{3} J_{\mathrm{H} 2, \mathrm{H} 3} / \mathbf{H z}$} \\
\cline { 2 - 3 } & Acetonitrile & Tris Buffer \\
\hline 1a & 6.60 & 6.43 \\
1b & 10.14 & 9.88 \\
1c & 5.39 & 5.11 \\
\hline
\end{tabular}

Table 3. Characteristic NOE contacts for $1 \mathbf{a}-\mathbf{c}$ in free and bound states.

\begin{tabular}{|c|c|c|c|c|c|c|c|c|c|}
\hline \multirow{3}{*}{ NOE Contact } & \multicolumn{9}{|c|}{ Compound } \\
\hline & \multicolumn{3}{|c|}{ 1a } & \multicolumn{3}{|c|}{$1 b$} & \multicolumn{3}{|c|}{ 1c } \\
\hline & acet. $^{a}$ & Tris $\mathbf{b}$ & rib. ${ }^{c}$ & acet. $^{a}$ & Tris $b$ & rib. ${ }^{c}$ & acet. $^{a}$ & Tris $b$ & rib. ${ }^{c}$ \\
\hline H3-H11 & - & - & - & - & - & - & - & - & - \\
\hline H4-H11 & + & + & + & + & + & + & + & + & + \\
\hline $\mathrm{H} 2-\mathrm{H} 4$ & + & + & + & + & + & + & + & + & + \\
\hline H4-H6Me & - & - & - & - & - & - & - & - & - \\
\hline H3-H8 & - & - & - & - & - & - & - & - & - \\
\hline H5-H6Me & + & + & + & + & + & + & + & + & + \\
\hline H8-H11 & - & - & - & - & - & - & - & - & - \\
\hline
\end{tabular}

${ }^{a}$ free state in acetonitrile- $\mathrm{d}_{3}$ solution; ${ }^{\mathrm{b}}$ free state in Tris- $\mathrm{d}_{11}$ buffer solution; ${ }^{\mathrm{c}}$ ribosome-bound state.

We also recorded ${ }^{13} \mathrm{C}$ and ${ }^{15} \mathrm{~N}$ CPMAS solid-state NMR spectra of the precursors and azithromycin, which are displayed in Figures 1 and 2 . CPMAS ${ }^{13} \mathrm{C}$ spectra were compared with ${ }^{13} \mathrm{C}$ DEPTQ spectra recorded in chloroform-d solution (Figure 1). Substantial line-broadening observed in solid-state spectra clearly demonstrates that 4"-aminopropyl derivative is amorphous, while others are present in ordered crystalline forms. The ${ }^{13} \mathrm{C}$ chemical shifts in solid state resemble those obtained in solution, reflecting similar conformations. The analysis of the ${ }^{15} \mathrm{~N}$ CPMAS spectra also pointed toward the same conclusions.

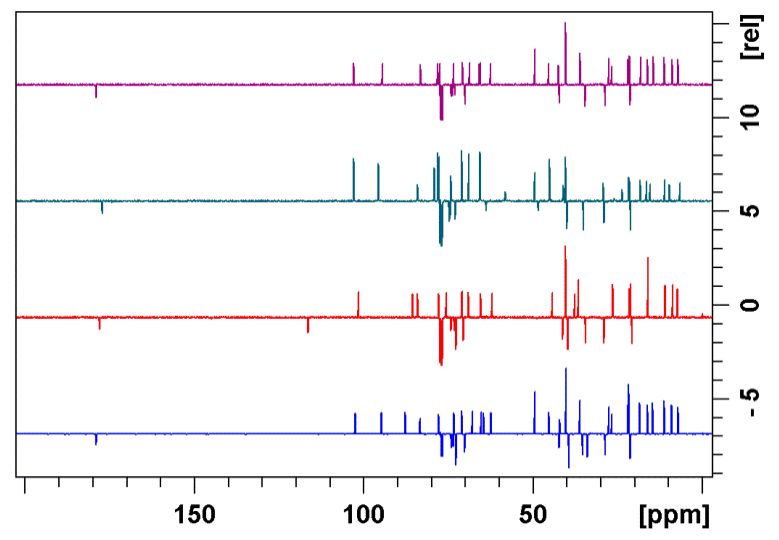

(a)

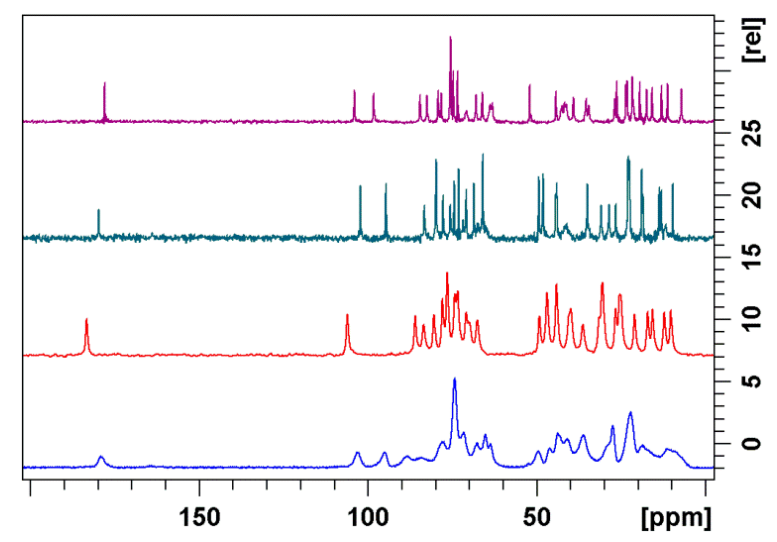

(b)

Figure 1. (a) Solution-state multiplicity-edited ${ }^{13} \mathrm{C}$ DEPTQ and (b) solid-state ${ }^{13} \mathrm{C} C P M A S$ NMR spectra of azithromycin, 1a, $\mathbf{1 b}$ and $1 \mathrm{c}$ (from top to bottom). 


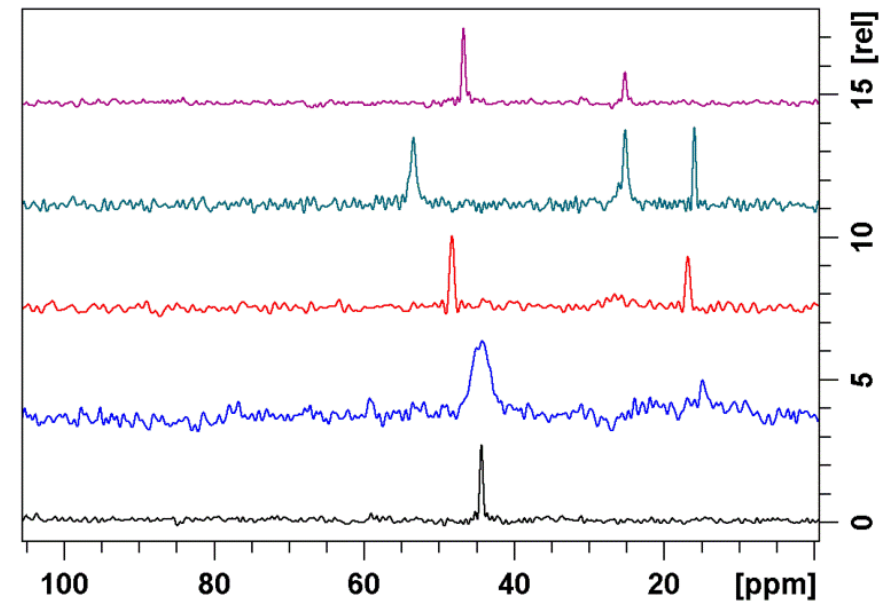

Figure 2. Solid-state ${ }^{15} \mathrm{~N}$ CPMAS NMR spectra of azithromycin, $\mathbf{1 a}, \mathbf{1} \mathbf{b}, \mathbf{1 c}$ and azithromycin algycone (from top to bottom).

${ }^{15} \mathrm{~N}$ chemical shifts of $\mathbf{1 a}-\mathbf{c}$ can readily be assigned by comparison with those of azithromycin and azithromycin aglycone (Figure 2). Hence, desosamine ${ }^{15} \mathrm{~N}$ chemical shifts are observed in the region between 45 and $50 \mathrm{ppm}$, while aminopropyl nitrogen atoms are found the most up-field (around $15 \mathrm{ppm}$ ). Nitrogen at position 9a exhibits intermediate chemical shift values $(\approx 25 \mathrm{ppm})$.

\subsection{Bound Structures and Interactions with E. coli Ribosome}

By using NMR spectroscopy, we sought to establish whether aminopropyl-azithromycin derivatives interact with the E. coli ribosome and what are their binding epitopes. We were also interested in possible structural changes that might occur upon the binding to ribosome.

The vast majority of NOE signals observed for 1a-c bound to ribosomes resemble those found in solution indicating similar conformations. The representative ROESY spectrum of $\mathbf{1 b}$ superimposed onto trNOESY spectrum in the presence of ribosome is displayed in Figure 3. It is clearly demonstrated that majority of the cross peaks are identical and that NOE contacts indicative of the folded-out structure such as $\mathrm{H} 4-\mathrm{H} 11, \mathrm{H} 2-\mathrm{H} 4$ and $\mathrm{H} 5-$ H6Me are present in both spectra (Figure 4). TrNOESY spectra of the compounds 1a and 1c also resemble NOESY spectra, showing that the dominant bound conformations are 3-endo-folded-out. Indicative NOE contacts are displayed in Table 3.

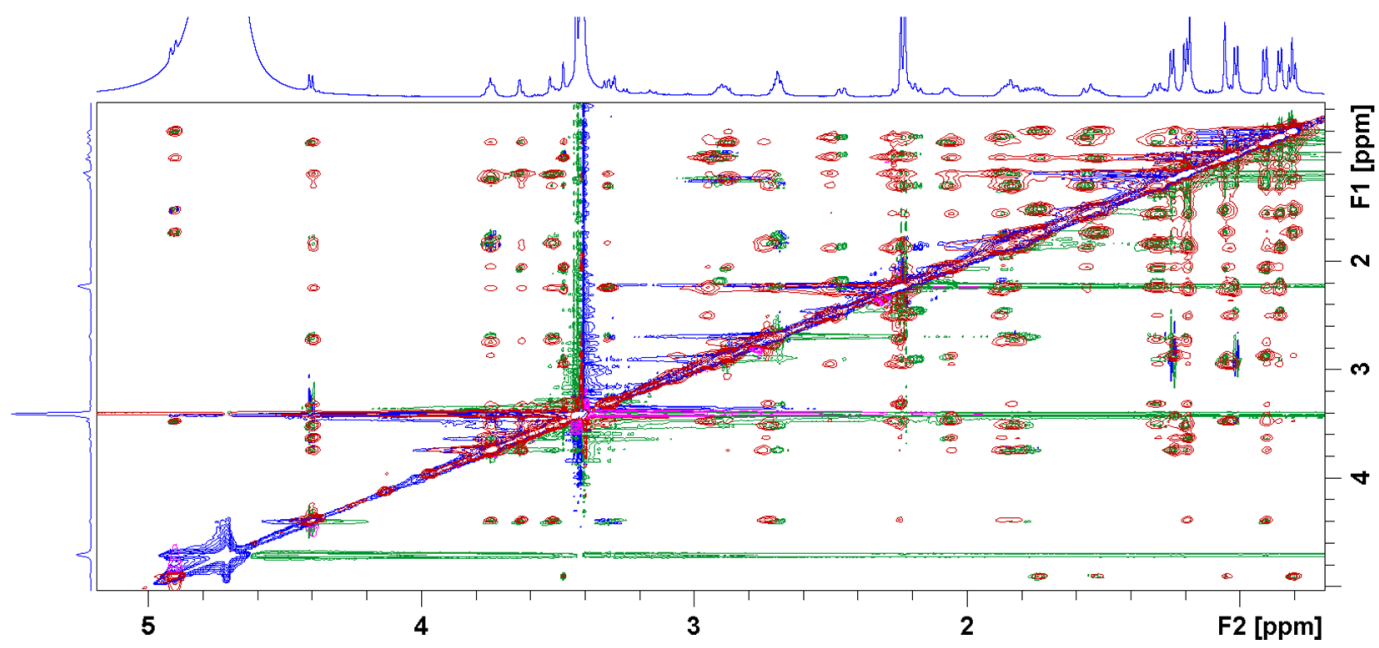

Figure 3. ROESY (blue and green signals) and trNOESY (red and pink signals) spectrum of $\mathbf{1 b}$ in Tris- $\mathrm{d}_{11}$ buffer (pH 7.4) prior to and after addition of the E. coli ribosome, respectively. 


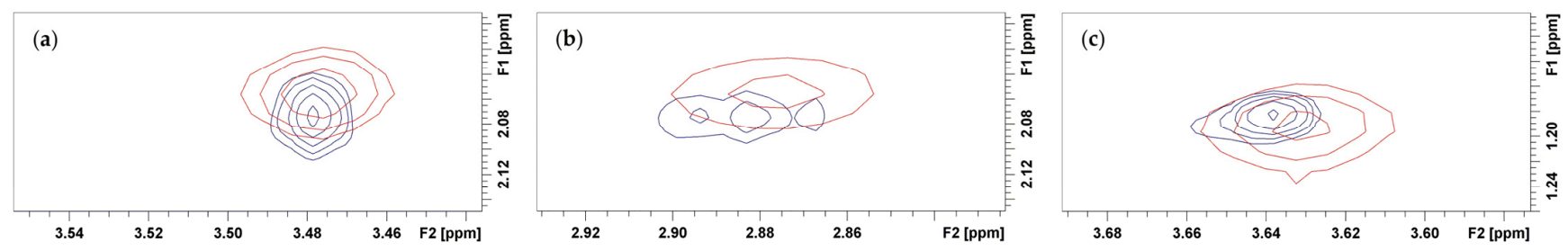

Figure 4. Free (blue) and bound-state (red) NOE cross peaks indicative of the folded-out conformation: (a) H4-H11; (b) $\mathrm{H} 2-\mathrm{H} 4$; and (c) H5-H6Me.

The compounds 1a-c were further subjected to STD experiments in the presence of E. coli ribosomes, to detect structural parts in intimate contact with the ribosome and to determine the binding epitopes. The chemical groups that exhibited STD enhancements are displayed in green and red and are given in Figures 5 and 6. The highest saturation transfers in compound $\mathbf{1 b}$ were observed for methyl groups at positions $3^{\prime}$ and 14 and a methylene group at position $3 c$ (green). An appreciable STD effect was also observed for methyl groups at positions $5^{\prime}, 6,8,10$ and 12 .
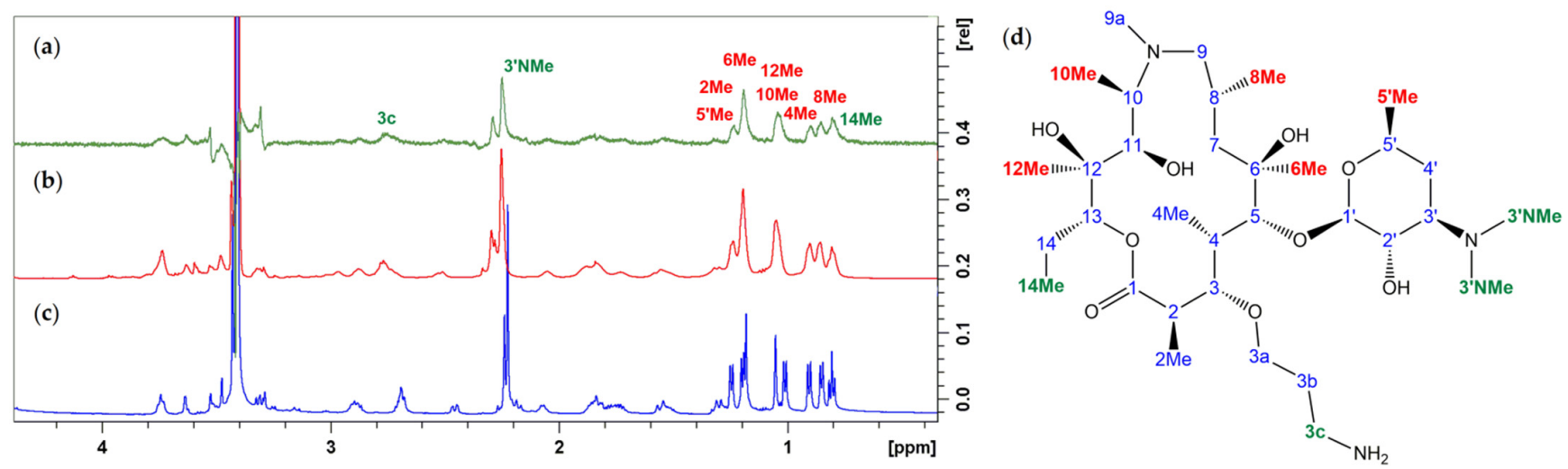

Figure 5. (a) STD difference spectrum for $\mathbf{1 b}$ after ribosome addition; (b) STD off-resonance spectrum after ribosome addition; (c) proton spectrum prior to ribosome addition; (d) chemical structure, atom numbering and binding epitopes (green and red) of $\mathbf{1 b}$.

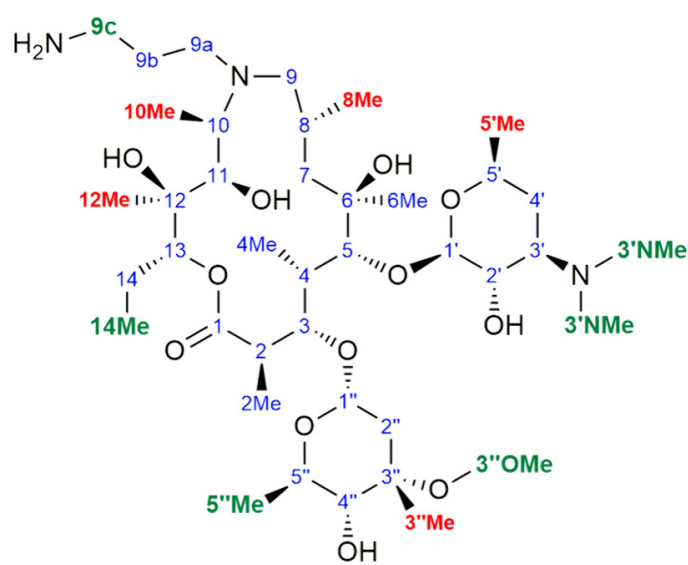

(a)

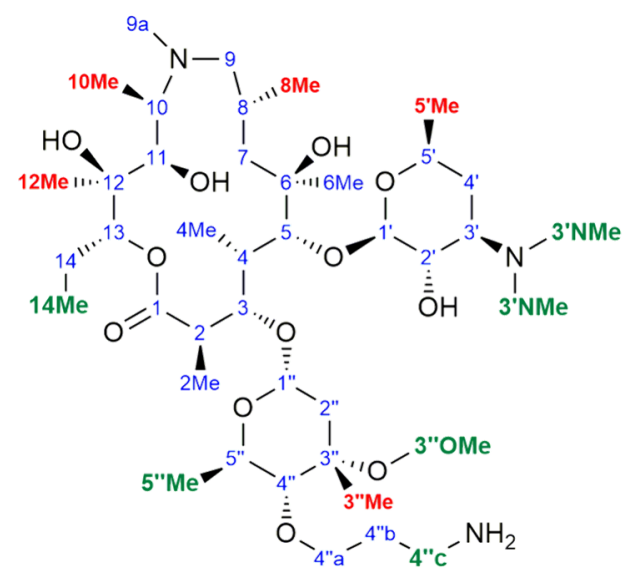

(b)

Figure 6. Chemical structure, atom numbering and binding epitopes (green and red) of (a) 1a and (b) 1c.

Similarly, the strongest STD enhancements in compounds 1a and 1c were observed for the same groups (Figure 6). Saturation transfers were also observed for methyl protons at positions $3^{\prime \prime}$ and $5^{\prime \prime}$ in the cladinose sugar, a moiety that is not present in $\mathbf{1 b}$. 
Hence, trNOESY and STD experiments have shown that all three aminopropylazithromycin derivatives bind to the ribosome, and that bound conformations are similar to free ones. A comparison between STD enhancements in $\mathbf{1 a - c}$ revealed common regions in close proximity to the ribosomal surface resembling those previously reported for azithromycin and some other 15-membered macrolides [10]. Additional STD effects were observed for methylene protons of the aminopropyl groups, also indicating that $\mathrm{NH}_{2}$ protons interact with the ribosome, but they cannot be observed in the spectra owing to exchange with deuterium from the solvent. These new contacts further contribute to the overall binding energy.

\subsection{Molecular Docking}

Docking study revealed that investigated compounds bind to the ribosome in the same binding pocket as erythromycin in the crystal structure of E. coli (PDB code: 4V7U). The primary binding sites of $\mathbf{1 a}$ are shown in Figure 7.

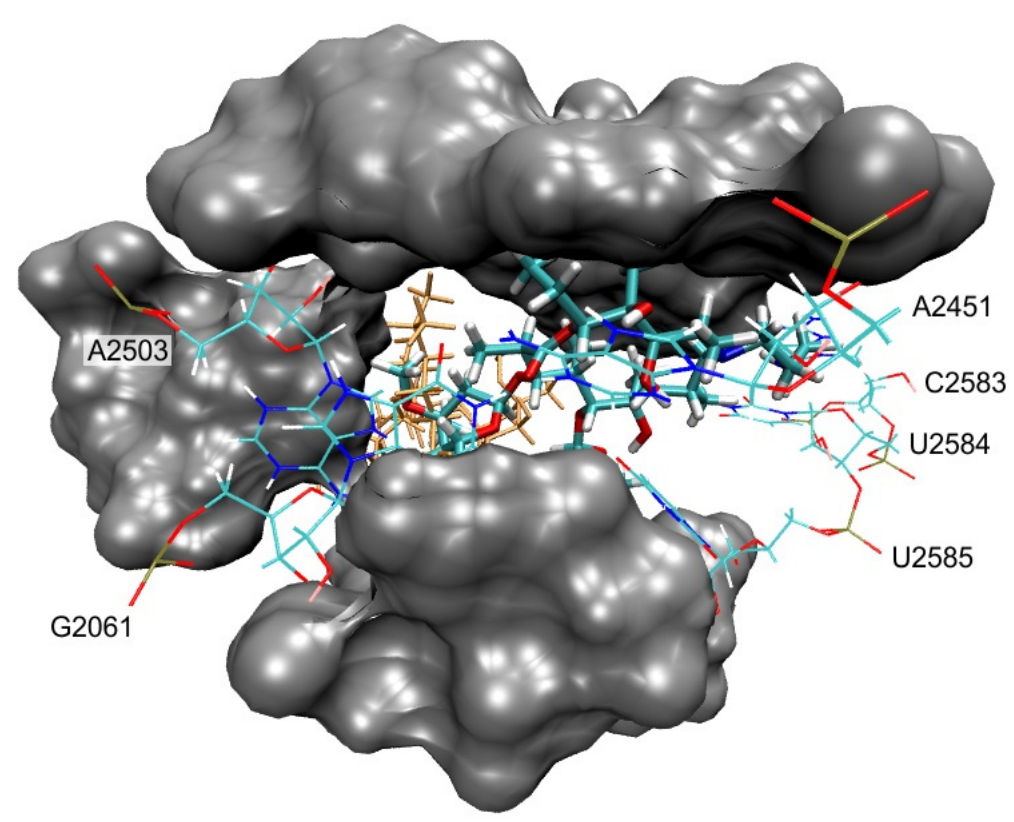

Figure 7. E. coli ribosome-binding mode of 1a that corresponds to the AZI-1 primary binding site [5]. Erythromycin found in the crystal structure (PDB code: $4 \mathrm{V7U}$ ) is shown as sticks and colored orange. Nucleotides with which compound 1a forms H-bonds are shown as wires and labeled. Binding site residues forming van der Waals interactions with 1a (A2058, A2059, A2503, U2504, G2505, U2506, A2062, C2063, C2452, U2584, U2585 and U2586) are shown as grey surfaces.

Also, additional binding sites were detected, but those were less frequent and considered as unspecific binding modes, so we focused on the binding modes that were in the same binding pocket as erythromycin in the crystal structure of E. coli. Similar binding modes were found for all three studied azithromycin derivatives and corresponded to the AZI-1 primary binding site as defined by Schlünzen et al. [5]. The macrolactone ring was in a similar position as found in the erythromycin crystal structure (Figure 7), e.g., in the folded-out conformation. Binding was mostly achieved by van der Waals interactions with nucleotides: A2058, A2059, A2503, U2504, G2505, U2506, A2062, C2063, C2452, U2584, U2585 and U2586. The binding specificity of the studied macrozones was achieved through H-bonds with the following nucleotides: A2503, G2061, A2451, C2583, U2584 and U2585 (Figure 7). In some binding modes, aminopropyl moiety enhances binding by making additional interactions with the ribosome; these contacts are highlighted in Figure 8. Although similar interactions with the ribosome were computationally found for all three compounds, their binding affinities differed. More favorable binding affinities in the erythromycin binding pocket were calculated for compounds $1 \mathbf{a}(-10.2 \mathrm{kcal} / \mathrm{mol})$ 
and $1 \mathrm{c}(-9.6 \mathrm{kcal} / \mathrm{mol})$ than for compound $1 \mathrm{~b}(-8.3 \mathrm{kcal} / \mathrm{mol})$. Differences in calculated binding affinities were in accordance with the experimental differences in activities against E. coli (Table 1).

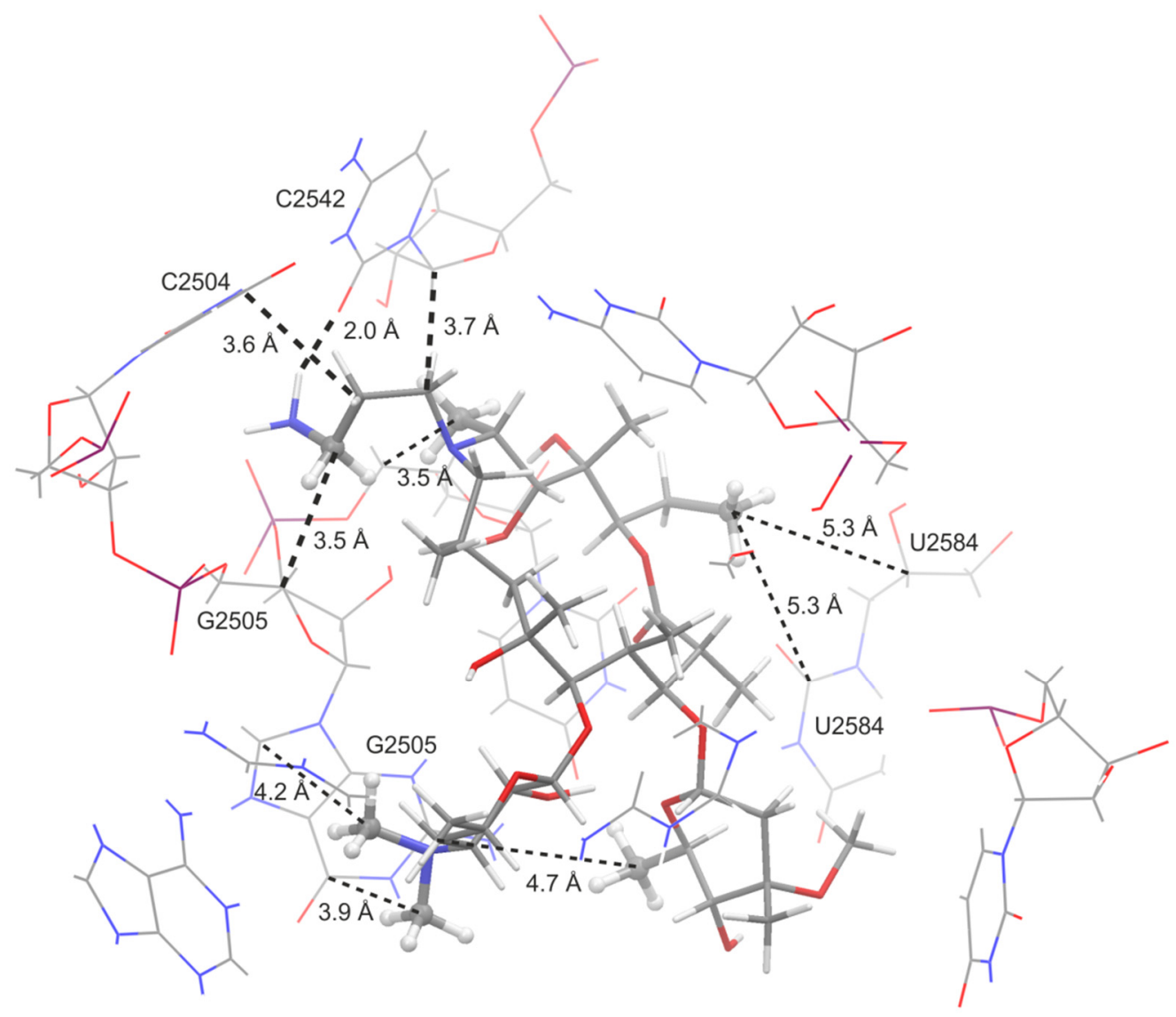

Figure 8. Interactions of $1 \mathbf{a}$ and the main contacts with E. coli ribosome nucleotides. The contacts observed in STD experiments and docking calculations are shown as dashed lines, and the interactions between the ribosome and aminopropyl moiety are highlighted as thicker dashed lines.

\section{Conclusions}

We have demonstrated that NMR spectroscopy and docking study can provide valuable data on the conformation and binding interactions of aminopropyl- azithromycin derivatives, precursors in the synthesis of bioactive macrozones. All compounds adopted similar conformations in free and bound states. Binding epitopes resemble those found for erythromycin, azithromycin and related 15 -membered macrolides. These results can further be exploited in the process of designing novel macrolide derivatives with activity against resistant pathogens.

Author Contributions: Conceptualization, P.N.; methodology, I.M., T.J., B.B., J.P.V., I.K. and P.N.; software, B.B.; formal analysis, I.M.,T.J. and B.B.; investigation, I.M., T.J., B.B., J.P.V., I.K. and P.N.; resources, P.N. and J.P.V.; data curation, I.M., T.J., B.B., J.P.V. and P.N.; writing—original draft preparation, I.M., T.J., B.B. and P.N.; visualization, I.M., T.J. and B.B.; supervision, P.N.; project administration, P.N.; funding acquisition, P.N. All authors have read and agreed to the published version of the manuscript.

Funding: This research was funded by the Croatian Science Foundation, grant number: HRZZ IP-2018-01-8098, The macrozones.

Institutional Review Board Statement: Not applicable.

Informed Consent Statement: Not applicable. 
Acknowledgments: We are grateful to Hana Čipčić Paljetak for performing in vitro antibacterial tests and Mirjana Bukvić for helpful discussions.

Conflicts of Interest: The authors declare no conflict of interest.

\section{References}

1. Grgičević, I.; Mikulandra, I.; Bukvić, M.; Banjanac, M.; Radovanović, V.; Habinovec, I.; Bertoša, B.; Novak, P. Discovery of macrozones, new antimicrobial thiosemicarbazone-based azithromycin conjugates: Design, synthesis and in vitro biological activity. Int. J. Antimicrob. Agents 2020, 56, 106147. [CrossRef] [PubMed]

2. Jednačak, T.; Mikulandra, I.; Novak, P. Advanced methods for studying structure and interactions of macrolide antibiotics. Int. J. Mol. Sci. 2020, 21, 7799. [CrossRef]

3. Arsić, B.; Barber, J.; Novak, P. The macrolide antibiotics and their semi-synthetic derivatives. In Macrolides: Properties, Synthesis and Applications; Arsić, B., Ed.; Walter de Gruyter GmbH: Berlin, Germany; Boston, MA, USA, 2018; pp. 1-30. [CrossRef]

4. Chancey, S.T.; Zhou, X.; Zähner, D.; Stephens, D.S. Induction of efflux-mediated macrolide resistance in Streptococcus pneumoniae. Antimicrob. Agents Chemother. 2011, 55, 3413-3422. [CrossRef] [PubMed]

5. Schlünzen, F.; Harms, J.M.; Franceschi, F.; Hansen, H.A.S.; Bartels, H.; Zarivach, R.; Yonath, A. Structural basis for the antibiotic activity of ketolides and azalides. Structure 2003, 11, 329-338. [CrossRef]

6. Tu, D.; Blaha, G.; Moore, P.B.; Steitz, T.A. Structures of $\mathrm{MLS}_{\mathrm{B}} \mathrm{K}$ antibiotics bound to mutated large ribosomal subunits provide a structural explanation for resistance. Cell 2005, 121, 257-270. [CrossRef] [PubMed]

7. Dunkle, J.A.; Xiong, L.; Mankin, A.S.; Cate, J.H.D. Structures of the Escherichia coli ribosome with antibiotics bound near the peptidyl transferase center explain spectra of drug action. Proc. Natl. Acad. Sci. USA 2010, 107, 17152-17157. [CrossRef]

8. Novak, P.; Banić Tomišić, Z.; Tepeš, P.; Lazarevski, G.; Plavec, J.; Turkalj, G. Conformational analysis of oleandomycin and its 8-methylene-9-oxime derivative by NMR and molecular modeling. Org. Biomol. Chem. 2005, 3, 39-47. [CrossRef] [PubMed]

9. Novak, P.; Tatić, I.; Tepeš, P.; Koštrun, S.; Barber, J. Systematic approach to understanding macrolide-ribosome interactions: NMR and modeling studies of oleandomycin and its derivatives. J. Phys. Chem. A 2006, 110, 572-579. [CrossRef] [PubMed]

10. Novak, P.; Barber, J.; Čikoš, A.; Arsić, B.; Plavec, J.; Lazarevski, G.; Tepeš, P.; Košutić-Hulita, N. Free and bound state structures of 6-O-methyl homoerythromycins and epitope mapping of their interactions with ribosomes. Bioorg. Med. Chem. 2009, 17, 5857-5867. [CrossRef] [PubMed]

11. Kosol, S.; Schrank, E.; Krajačić, M.B.; Wagner, G.E.; Meyer, N.H.; Göbl, C.; Rechberger, G.N.; Zangger, K.; Novak, P. Probing the interactions of macrolide antibiotics with membrane-mimetics by NMR spectroscopy. J. Med. Chem. 2012, 55, 5632-5636. [CrossRef]

12. Glanzer, S.; Pulido, S.A.; Tutz, S.; Wagner, G.E.; Kriechbaum, M.; Gubensäk, N.; Trifunović, J.; Dorn, M.; Fabian, W.M.F.; Novak, P.; et al. Structural and functional implications of the interaction between macrolide antibiotics and bile acids. Chem. Eur. J. 2015, 21, 4350-4358. [CrossRef]

13. Novak, P.; Tepeš, P.; Lazić, V. Epitope mapping of macrolide antibiotics to bovine serum albumin by saturation transfer difference NMR spectroscopy. Croat. Chem. Acta 2007, 80, 211-216.

14. Novak, P. Interactions of macrolides with their biological targets. In Macrolides: Properties, Synthesis and Applications; Arsić, B., Ed.; Walter de Gruyter GmbH: Berlin, Germany; Boston, MA, USA, 2018; pp. 63-77. [CrossRef]

15. Morris, G.M.; Huey, R.; Lindstrom, W.; Sanner, M.F.; Belew, R.K.; Goodsell, D.S.; Olson, A.J. AutoDock4 and AutoDockTools4: Automated docking with selective receptor flexibility. J. Comput. Chem. 2009, 30, 2785-2791. [CrossRef] [PubMed]

16. Trott, O.; Olson, A.J. AutoDock Vina: Improving the speed and accuracy of docking with a new scoring function, efficient optimization and multithreading. J. Comput. Chem. 2010, 31, 455-461. [CrossRef]

17. Humphrey, W.; Dalke, A.; Schulten, K. VMD: Visual molecular dynamics. J. Mol. Graph. 1996, 14, 33-38. [CrossRef] 